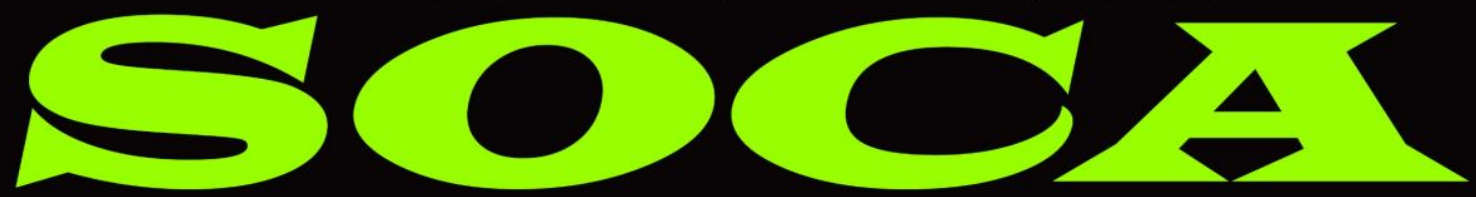

JOURNAL ON SOCIAL ECONOMICS OF AGRICULTURE

Vol.12 No.2 31 Desember 2018

e-ISSN: $2615-6628$

p-ISSN: $1411-7176$

\title{
MANAJEMEN DAN TATA KELOLA KEBUN PERCOBAAN FAKULTAS PERTANIAN UNIVERSITAS UDAYANA
}

\author{
I Gusti Alit Gunadi \\ Program Studi Agroekoteknologi Fakultas Pertanian Universitas Udayana \\ E-mail: gunadiya@gmail.com \\ HP: 087860825410
}

\begin{abstract}
ABSTRAK
Kebun Percobaan Fakultas Pertanian (KPFP) UNUD pada awalnya yang hanya mempunyai fungsi utama untuk keperluan edukasi, seiring dengan berjalannya waktu dan perkembangan jaman. Fakultas Pertanian Unud melalui pengelola mencoba menambahkan fungsi ekonomi yang menjadi tujuan diharapkan sejalan dengan perkembangan inovasi dan teknologi yang dihasilkan KPFP kedepannya. Sangat penting untuk mengelola KPFP dengan manajemen yang teratur, terarah, dan berkesinambungan. Untuk dapat mewujudkan hal ini, tentu memerlukan dukungan fasilitator di bidang pendanaan dan kaji terap teknologi untuk selalu bersinergi dalam upaya mengatasi kendala yang selama ini menghimpitnya.
\end{abstract}

Kata Kunci: Kebun Percobaan, Manajemen dan Tata Kelola

\section{MANAGEMENT AND GOVERNANCE OF EXPERIMENTAL STATION FACULTY OF AGRICULTURE UDAYANA UNIVERSITY}

\begin{abstract}
The Faculty of Agriculture Experiment Garden (KPFP) at the beginning of the UNUD only had the main function for educational purposes, over time and the times. The Faculty of Agriculture, Unud, through the manager tries to add the economic functions that are the objectives expected to be in line with the development of innovation and technology produced by KPFP in the future. It is very important to manage KPFP with regular, directed and continuous management. To be able to realize this, of course, requires the support of facilitators in the field of funding and reviewing technology applications to always synergize in an effort to overcome the obstacles that have been hindering it.
\end{abstract}

Keywords: Experimental Station, Management and Governance

\section{PENDAHULUAN}

Kebun Percobaan

Pertanian (KPFP) UNUD tergolong berlahan basah dengan luas 1,7 hektar. Pada awalnya yang hanya mempunyai fungsi utama untuk keperluan edukasi meliputi penelitian dosen dan atau mahasiswa juga kegiatan praktikum beberapa 
matakuliah. Berbagai jenis kegiatan penelitian dan praktikum juga diyakini akan dapat menstimulasi aktivitas mahasiswa untuk belajar berkreativitas dan menumbuhkan jiwa kewirausahaan dikalangan mahasiswa. Sehingga kegiatankegiatan tersebut memberikan pengalaman dan pemahaman bagi mahasiswa untuk dapat meningkatkan kompetensi lulusan/sarjana pertanian sesuai kompetensi lulusan yang ditargetkan Fakultas Pertanian Unud. Kompetensi mahasiswa FP yang dimaksud dalam hal ini, meliputi teknik budidaya, kewirausahaan, dan penataan tampilan/estetika. Karena lahan KPFP hanya berfungsi sebagai wahana edukasi, pemanfaatan lahan KPFP menjadi belum optimal, karena tidak semua lahan dapat terolah dan terpelihara dengan baik, akibat keterbatasan dana. Sumber dana untuk pengelolaan lahan hanya bersumber dari dana praktikum dan penelitian dosen/mahasiswa.

Fakultas Pertanian Unud melalui pengelola KPFP, berupaya merubah pola pikir yang selama ini menganggap fungsi KPFP hanya sebagai wahana edukasi, kini mencoba menambahkan fungsinya. Fungsi KPFP yang ingin ditargetkan adalah fungsi ekonomi namum tentunya bukan kepentingan ekonomi murni yang semata-mata mentargetkan keuntungan maksimum. Fungsi ekonomi yang menjadi tujuan diharapkan sejalan dengan perkembangan inovasi dan teknologi yang dihasilkan KPFP kedepannya. Sehingga kedepannya KPFP menjadi tertata dan termanajemen secara baik dan mampu mendanai kegiatannya secara mandiri sesuai apa yang telah direncanakan.

KPFP memiliki potensi dan peluang-peluang yang cukup besar untuk berkembang lebih baik. Potensi yang dimiliki antara lain sumberdaya lahan yang subur dengan skala ekonomi yang relatif luas, sehingga dengan sedikit perlakuan pada tanah maka lahan siap ditanami dengan jenis-jenis tanaman dataran rendah. Sumberdaya manusia yang dimiliki FP UNUD sangat baik, terbukti dari terdapatnya beberapa teknologi dan inovasi-inovasi yang dihasilkan oleh para dosen di kalangan FP UNUD yang siap membantu dan mendukung kemajuan KPFP.

Pesatnya perkembangan pembangunan di Kota Denpasar berdampak positif bagi perkembangan KPFP. Lokasi kebun yang sangat strategis yaitu dekat dengan perumahan penduduk, pertokoan, dan juga pasar tradisional, sehingga pasar untuk hasil produksi kebun sangat potensial untuk direbut. Dengan demikian, areal pertanian/kebun yang berada di kawasan perkotaan dapat dioptimalkan pemanfaatannya untuk berproduksi.

Fakultas Pertanian Universitas Udayana melalui pengelola KPFP yang memiliki visi untuk menjadi "center of excellen'" di bidang pertanian akan mewujudkan satu unit kegiatan yang dapat dijadikan contoh pengembangan berbagai teknologi di bidang pertanian. Untuk itu, diharapkan di kemudian hari masyarakat akan dapat menjadikan unit kegiatan ini sebagai acuan untuk pengembangan teknologi kreatif sebagai alternatif pengembangan pertanian perkotaan. Di samping untuk dijadikan acuan/ percontohan di bidang pertanian, FP UNUD berkomitmen menjadikan 
pertanian merupakan peluang kerja yang memiliki citra mulia, bersih, dan menjanjikan kesejahteraan di masa kini dan masa mendatang. Dampak lain yang diharapkan adalah akan terwujudnya kajian-kajian yang mengarah pada peningkatan kemampuan sumber daya manusia pertanian dengan menjadikan unit ini sebagai tempat pembelajaran dan pelatihan keterampilan bagi siswa yang ada di Kota Denpasar dan Bali umumnya, bagi mahasiswa Fakultas Pertanian Universitas Udayana, dan masyarakat secara luas. Begitu pula dengan adanya unit ini diharapkan akan dapat dijadikan unit konservasi bagi plasma nutfah yang terus mengalami degradasi dari tahun ke tahun.

Melihat uraian analisis situasi tersebut di atas, maka memang sangat penting untuk mengelola KPFP menggunakan manajemen yang teratur, terarah, dan berkesinambungan. Untuk dapat mewujudkan hal ini, tentu memerlukan dukungan fasilitator di bidang pendanaan dan kaji terap teknologi untuk selalu bersinergi dalam upaya mengatasi kendala yang selama ini menghimpitnya.

Setelah melihat kenyataan pada latar belakang di atas terutama yang dikaitkan dengan kekuatan dan peluang yang dimiliki KPFP untuk dapat berkembang kearah kemandirian, maka program yang ingin direncanakan oleh Fakultas Pertanian Unud melalui pengelola kebun adalah "pengembangan kegiatan pertanian produktif, edukasi, dan pengadaan tanaman koleksi" ini akan menjadi hal yang sangat penting untuk mendukung fungsi kebun sebagai wahana edukasi, ekonomi, dan estetika. Melalui kegiatan ini nantinya diharapkan dapat mewujudkan sebuah unit kegiatan pertanian dengan menggunakan teknologi yang baik di bidang pertanian dalam satu luasan yang memungkinkan.

\section{SEJARAH KPFP UNIVERSITAS UDAYANA}

Kebun Percobaan Fakultas Pertanian Universitas Udayana yang dikenal sebagai KPFP memiliki Luas dan lokasi $(1,7025$ ha, Subak Kerdung-Kecamatan Denpasar Selatan, \pm 25 mdpl, $6 \mathrm{~km}$ dari kampus Udayana PB Sudirman yang dapat ditempuh 15 menit dengan kendaraan bermotor). Lokasi ini pada awalnya merupakan areal persawahan, namun sejalan dengan perkembangan pembangunan lahan sekitarnya beralih fungsi menjadi pemukiman. Perubahan fungsi lahan di sekitarnya menjadikan lokasi kebun percobaan berubah menjadi lahan kering selahan hingga saat ini.

Atas prakarsa Prof. Dr. Ida Bagus Mantra sebagai rektor pertama UNUD, Fakultas Pertanian berdasarkan SK Dirjren Dikti Nomor 102 Tahun 1967. Surat keputusan tersebut menegaskan bahwa FP UNUD hanya boleh menamatkan mahasiswa sampai gelar Sarjana Muda (B.Sc.).

Sebagaimana lazimnya sebuah Fakultas Pertanian, sudah barang tentu membutuhkan lokasi aplikasi teori dalam kelas baik di laboratorium maupun penerapan lapang. Aplikasi teori di lapangan bisa dalam bentuk praktikum atau penelitian. Atas prakarsa dekan saat itu (Ir. Putu Djapa Winyaya, M. Sc) diupayakan melakukan pendekatan ke Pemerintah Kabupaten Badung untuk memohon lahan guna mengakomodir kebutuhan lahan percobaan. Upaya untuk https://doi.org/10.24843/SOCA.2018.v12.i02.p02 
memperlancar proses permohonan lahan, merasa sangat terbantu oleh A.A. Ketut Djelantik yang pada saat itu menduduki jabatan Kepala Biro Pemerintahan di Kantor Gubernur Prop. Bali. Atas kerjasama dan bantuan beliau, pada tahun $1970 \mathrm{FP}$ Unud diberikan lahan sawah \pm 2 ha di Subak Kerdung dengan status Hak Guna Pakai.

Peruntukan lahan pada awalnya digunakan sebagaimana fungsinya, penanaman padi tetap dilaksanakan karena irigasi sangat mendukung. Pemanfaatan lahan kebun diawali dengan bangunan sebuah Gudang, sebuah ruang kuliah/asistensi dilengkapi dengan kamar mandi dan toilet. Sebagai pengelola saat itu adalah Bapak Dekan yang dibantu oleh I Wayan Suena, BSc. serta di back-up oleh seorang tenaga kebun yaitu Bapak Guru Manggis (berasal dari Pedungan) dan menetap di lokasi lokasi kebun. Sistim pengelolaan dengan penjaga kebun diatur dengan sistem bagi hasil, sehingga ada pemasukan bagi pengelola untuk bergeliat.

Mengingat keterbatasan yang ada dan tuntutan kompetensi lulusan secara akademik, KPFP mendapat sentuhan yang signifikan terhitung sejak tahun 2012. Organisasi pengelola ditata untuk memenuhi kebutuhan secara akademis (tridharma) dan non akademis (income generating) termasuk melengkapi sarana dan prasarana standar minimal sebuah kebun percobaan Fakultas Pertanian. Pimpinan dan Kebijakan pengelola silih berganti seirama dengan perjalan sang kala sebagai berikut:

1. Ir. I Nyoman Sutedja

2. Ir. W. Sudarka, MP.

3. Ir. I Dewa Nyoman Nyana

https://ojs.unud.ac.id/index.php/soca
4. Ir. I Gusti Ngurah Raka MS.

5. Ir. I Wayan Dana Atmaja, MP

6. Ir. I Gusti Alit Gunadi, MS. (SK Rektor Unud terhitung mulai 4 Januari 2012)

Sejak lama keberadaan kebun belum mendapat sentuhan dan curahan yang signifikan mengingat keterbatasan yang ada secara institusi dan baru dirasakan mendapat sentuhan yang romantis dari pihak lembaga terhitung sejak tahun 2012. Atas prakarsa Dekan Fakultas Pertanian Prof. Dr. Ir. I Nyoman Rai, MS. dan supporting penuh oleh Prof. Ir. I Ketut Budi Susrusa, MS. (selaku Wadir-2 Pasca Sarjana merangkap sebagai pengelola) ingin mewujudkan kebun percobaan yang layak untuk dikunjungi khususnya bagi insan pertanian. Langkah awal dimulai dengan memasukkan berbagai kegiatan yang relevan untuk melibatkan kegiatan akademik di Strata S-2 dan S-3 di lingkup Pertanian (sebagai lahan praktikum/lokasi penelitian S-2 Lahan Kering/Agroekoteknologi, S-2 Bioteknologi, dan S-3 Ilmu Pertanian). Penataan diawali dengan pembuatan gambar (zonasi blok) dan ditindak lanjuti dengan berbagai pembangunan fisik seperti dan kelenkapan sarana/prasarana seperti, tembok pembatas keliling, bangunan kelas/studio, Lab. kaca, alsintan, sarana irgasi pipa dan lain-lain. Berbagai kegiatan yang telah dikerjakan sejak terbitnya SK Rektor Unud No: 19/UN14.1.23/HK/2012, tentang Pembentukan Tim Pengelola Kebun FP-Unud.

\section{TATA KELOLA LAHAN}

Pada dasarnya pemanfaatan lahan KPFP diutamakan untuk pelaksanaan tridharma seperti 
praktikum mata kuliah, penelitian mahasiswa pertanian (S-1, S-2, dan S3) dan mahasiswa fakultas lainnya di lingkungan Universtas Udayana. Namun dalam kondisi tertentu masih tetap terbuka bagi mahasiswa yang ingin melakukan pengembangan ilmu di luar Unud bahkan juga dari pihak swasta, selama lahan masih memungkinkan. Adanya lahan yang belum tertanami, pihak pengelola mengupayakan untuk membudidayakan dengan berbagai jenis tanaman setahun. Waktu tenggang yang Panjang nampaknya secara rutin akan terulang pada akhir semester genap karena masa liburan mahasiswa. Kondisi ini menjadikan pengelolaan lahan dapat dioptimalkan oleh pengelola.

Optimalisasi pemanfaatan sumberdaya lahan dapat dilakukan dengan pendekatan secara terintegrasi sehingga dapat memfasilitasi berbagai konflik penggunaan lahan (Faisal dan Soeparno, 2018).

Optimalisasi pemanfaatan lahan pada saat tak digunakan untuk medukung kegiatan tridharma, diupayakan untuk budidaya inovatif seperti memproduksi jagung Mantan (manis ketan) yang merupakan persilangan secara alami antara jagung Manis dan jagung Ketan. Keberhasilan persilangan sangat ditentukan oleh pemulia tanaman mengenai tehnik persilangan itu sendiri maupun pada pengetahuan akan bunga, misalnya: stuktur bunga, waktu berbunga, saat bunga mekar, kapan bunga betina siap menerima bunga jantan (tepung sari), dan tipe penyerbukan (Juvita, 2014 dalam Muchammad, dkk., 2015).

Mengingat

antusiame permintaan akan Mantan, maka pihak pengelola mengupayakan produksi Mantan berkelanjutan. Upaya yang dilakukan adalah menanam secara simultan dalam luasan teretentu. Adanya perbedaan umur dari masingmasing jenis jagung yang akan disilangkan, menjadikan program penanaman disesuaikan dengan masa silking dan tasseling. Waktu tanam jagung manis 10 hari mendahulu penanaman jagung ketan, sehingga akan terjadi persilangan secara alamiah. Hal ini dapat dimungkinkan akan terjadi persilangan antar tanaman di lokasi saja, mengingat wilayah sekitarnya merupakan daerah pemukiman yang diyakini tidak ada penanaman jagung.

Sistem tanam yang berkesinambungan mewajibkan untuk menjaga sifat fisik, kimia, dan biologi tanah. Mengingat kondisi tanah di KPFP sering penggunaan pupuk anorganik, maka nampaknya pemupukan dengan bahan organik matang atau $\mathrm{C} / \mathrm{N}$ ratio yang tinggi, perlu dioptimalkan. Rasio $\mathrm{C} / \mathrm{N}$ yang tinggi menyebabkan immobilisasi $\mathrm{N}$ sehingga tersedia bagi mikroorganisme dan tanaman Awalita, dkk., 2006 dan Riwandi dkk, 2014). 
Tabel 1. Penanaman Jagung Mantan (Manis Ketan) Berlanjut

\begin{tabular}{|c|c|c|c|c|c|c|c|c|c|c|c|c|}
\hline \multirow{3}{*}{ PERIODE TANAM } & \multicolumn{11}{|c|}{ B U L A N / M I N G G U } & \multirow{3}{*}{$\begin{array}{c}\text { Pemakaian } \\
\text { Tenaga } \\
\text { (OH) }\end{array}$} \\
\hline & \multicolumn{4}{|c|}{ I } & \multicolumn{4}{|c|}{ II } & \multicolumn{3}{|c|}{ III } & \\
\hline & 1 & 2 & 3 & 4 & 1 & 2 & 3 & 4 & 1 & 2 & 3 & \\
\hline \multicolumn{13}{|l|}{ TANAM I $\left(300 \mathrm{~m}^{2}\right)$} \\
\hline - Olah tanah & $a$ & & & & & & & & & & & 2 \\
\hline \multicolumn{13}{|l|}{ - Tugal benih } \\
\hline Jagung Manis & & $a$ & & & & & & & & & & 1 \\
\hline Jagung Ketan & & & a & & & & & & & & & 1 \\
\hline - Pengairan & & $a$ & $a$ & a & $a$ & $a$ & a & $a$ & & & & 2 \\
\hline - $\quad$ Pemupukan+bumbun & $a$ & & & $a$ & & & $a$ & & & & & 2 \\
\hline - $\quad$ Pengendalian HPT *) & & & & & & & & & & & & 1 \\
\hline - Panen & & & & & & & & & & $a$ & & 1 \\
\hline & & & & & & & & & & & & \\
\hline TANAM II $\left(300 \mathrm{~m}^{2}\right)$ & & & & & & & & & & & & 1 \\
\hline - Tugal benih & & & & & & & & & & & & 1 \\
\hline Jagung Manis & & & $a$ & & & & & & & & & 2 \\
\hline Jagung Ketan & & & & $a$ & & & & & & & & 2 \\
\hline - Pengairan & & & $a$ & $a$ & $a$ & $a$ & $a$ & $a$ & $a$ & & & 1 \\
\hline - $\quad$ Pemupukan+bumbun & & $a$ & & & a & & & $a$ & & & & 1 \\
\hline - $\quad$ Pengendalian HPT *) & & & & & & & & & & & & 1 \\
\hline - Panen & & & & & & & & & & & $a$ & 1 \\
\hline
\end{tabular}

Sumber: Diolah dari data primer, 2018

Keterangan:

1. Sistem tanam dilakukan secara simultan/bersambungan.

2. Penanaman Jagung manis lebih awal 10 hari sebelum tanam Jagung Ketan.

3. Jarak tanam $40 \mathrm{~cm} \times 70 \mathrm{~cm}$ dengan 2 tanaman/lubang tugal, populasi 2143 tanaman/300m2, prediksi tongkol panen layak jual 90\% (1.929 tongkol).

4. Olah tanah tanam I menggunakan traktor tangan dan minimum tillage pada penanaman ke II, sehingga musim tanam II dapat mengurangi biaya olah tanah sebesar Rp 128640 dan $2 \mathrm{OH}$ tenaga kerja.

5. Tanam III dan IV dilakukan dengan cara yang sama seperti olah tanah I dan II.

6. Terlihat masa panen akan berlanjut pada bulan III (minggu 23), duplikasi saat penanaman dilakukan pada waktu tanam berikutnya (III - dst) dengan pola pengunduran waktu tugal benih 1 minggu. 
Tabel 2. Pembiayaan

\begin{tabular}{|c|c|c|}
\hline \multirow{2}{*}{ Pekerjaan } & \multicolumn{2}{|l|}{ Biaya Saprodi Tanam I } \\
\hline & Uraian & (Rp) \\
\hline - Olah tanah & $\begin{array}{l}\text { Bhn bakar traktor Rp. } 21.440 / \text { jam; (bajak } \\
\text { singkal dan rotary } 2 \mathrm{OH} \text { ) }\end{array}$ & 128640 \\
\hline - Tugal benih & $\begin{array}{l}2 \text { saset benih (Rp 90000/saset jagung } \\
\text { ketan, Rp } 115000 / \text { saset jagung manis); } 2 \\
\text { OH }\end{array}$ & 205000 \\
\hline - Pengairan & Bahan bakar mesin air (70.000); $2 \mathrm{OH}$ & 70000 \\
\hline - Pemupukan+bumbun & 350/ha kg NPK 16:16:16; 2 OH & 96600 \\
\hline \multirow[t]{4}{*}{ - $\quad$ Pengendalian HPT *) } & 1 set $(40.000) ; 1 \mathrm{OH}$ & 40000 \\
\hline & Biaya saprodi I & 540240 \\
\hline & Ongkos tenaga kerja (10 OH @Rp 100.000) & 1000000 \\
\hline & Total biaya & 1540240 \\
\hline \multirow[t]{2}{*}{ - Produksi } & $1.929 \times \mathrm{Rp} 1000 /$ tongkol & 1929000 \\
\hline & Saldo & 388760 \\
\hline
\end{tabular}

Sumber: Diolah dari data primer, 2018

Disamping penanaman jagung Mantan, pihak pengelola juga memanfaatkan lahan bera untuk mebudidayakan tanaman semusim lainnya seperti edamame (Glycin max (L) Merrill), gold melon (Cucumis melo L.), bunga gumitir (Tegetes erecta), dan tanaman sejenis lainnya dengan pola penanaman yang sama.

TATA KELOLA TENAGA KERJA KPFP

Kebun Percobaan Fakultas Pertanian dengan fasilitas yang tersedia dalam mendukung kegiatan penelitian dan praktikum agar dapat dikelola secara optimal, maka dilakukan penugasan beberapa staf dosen berdasarkan surat keputusan rektor. Tugas pokok dan fungsi penanggung jawab kebun percobaan seyogyanya meliputi pengelolaan sumber daya yang meliputi tenaga kerja, sarana dan prasarana serta anggaran serta penyiapan rencana kerja (Balitjestro, 2015). Para staf dosen yang ditugaskan memiliki kewajiban untuk merencanakan/membuat rencana kerja yang pelaksanaanya dilakukan oleh pekerja kebun. Susunan organisasi pengelola KPFP seperti terlihat pada gambar berikut: 


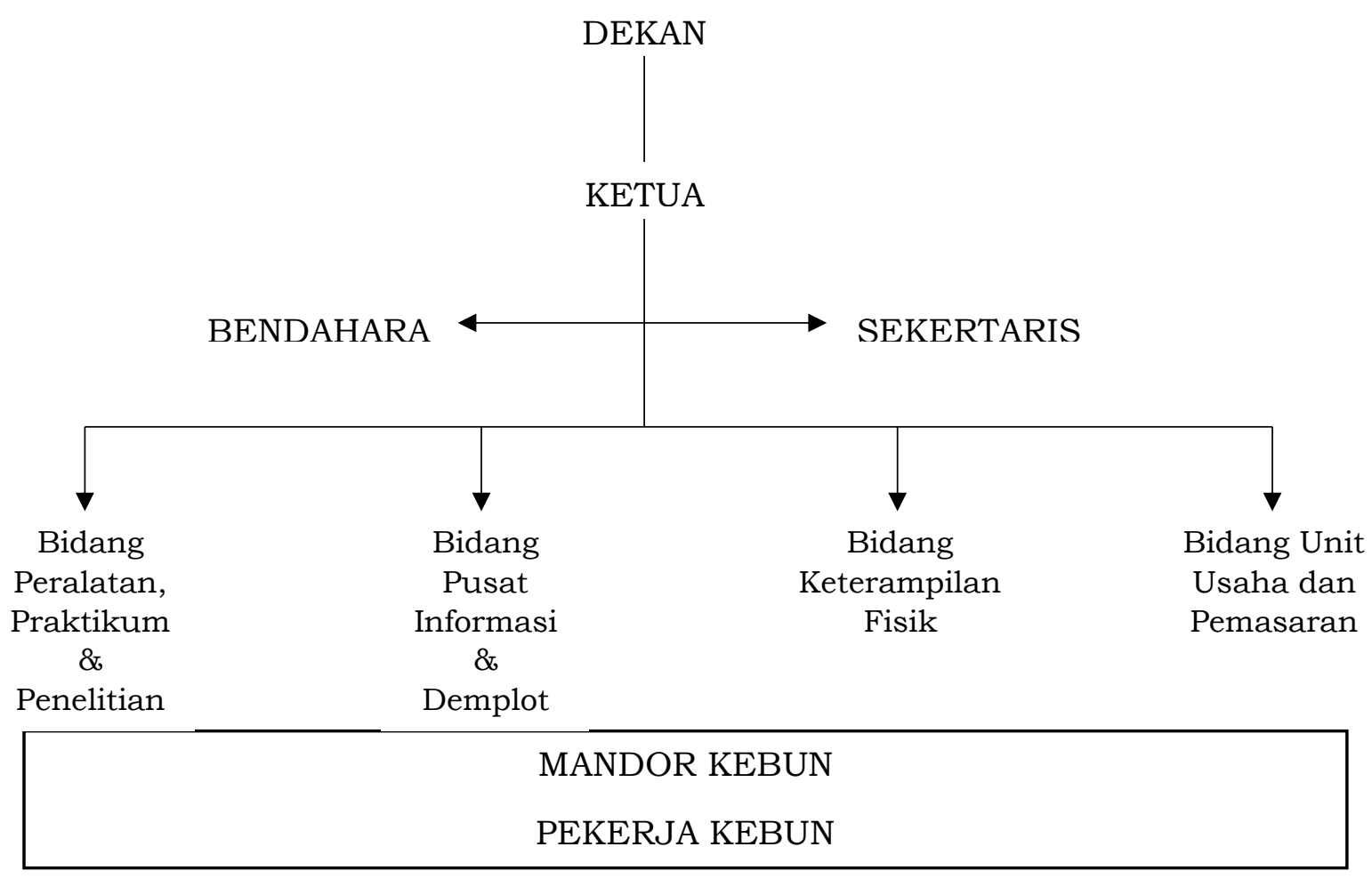

Gambar 1. Susunan organisasi pengelola KPFP

Penyediaan Sumberdaya manusia yang kompeten, yaitu SDM yang memiliki ketrampilan dan kecakapan yang memadai untuk melakukan suatu tugas yang diisyaratkan sehingga mampu menstabilkan performa, tindakan, perilaku, dan pikiran secara rasional dan efektif dalam implementasi (Anon, 2012). Hal ini nampaknya perlu dipersiapkan untuk mendukung tuntutan kompetensi lulusan FP UNUD khususnya berkaitan dengan pelaksanaan budidaya tanaman.

Optimalisasi proses produksi dan produksi tidak saja dipengaruhi oleh penyediaan SDM yang kompeten akan tetapi juga harus memperhatikan tingkat optimalisasi penggunaan SDM. Optimalisasi SDM hanya dapat dilakukan dengan melakukan perencanaan SDM yang memadai. Kepentingan dalam perencanaan SDM meliputi: kepentingan individu dan kepentingan organisasi pengelola, dan kepentingan lembaga.

Kepentingan individu khususnya bagi petugas kebun telah diupayakan dengan melaksanakan langsung kegiatan budidaya berbagai jenis komoditi dengan berbagai aplikasi teknologi yang mungkin dapat dilaksanakan sesuai ketersediaan sarana dan prasarana. Harapannya ke depan, pelaksanaan kegiatan praktikum dan kegiatan sejenisnya seperti edutain (pengenalan pertanian sejak usia dini), dapat dikerjakan secara baik dengan acuan pedoman/hand out yang disediakan.

\section{DAFTAR PUSTAKA}

Anon., 2012. Tantangan Penyediaan SDM Kompeten Dalam Mendukung Pembangunan Perkebunan di Indonesia. Kementrian Pertanian, Dirjen Perkebunan 
Awalita M., S. Darmanti, S. Parman. 2006. Produksi Tanaman Jagung Manis (Zea Mays L. Saccharata) yang Diperlakukan dengan Kompos Kascing dengan Dosis yang Berbeda Lab. Biologi Struktur dan Fungsi Tumbuhan Jurusan Biologi FMIPA UNDIP, Buletin Anatomi dan Fisiologi Vol. XIV, No. 2, Oktober 2006.

Balitjestro, 2015. Panduan Umum Pengelolaan Kebun Percobaan. BALITJESTRO Balitbang Kementrian Pertanian. http: / / balitjestro.litbang.perta nian.go.id/panduan-umumpengelolaan-kebun-percobaan/

Faisal, K dan H. Soeparno, S. 2018. Kerangka Perencanaan Tata
Guna dan Pengelolaan Lahan Pertanian. LITBANG Pertanian. https://www.kingsige.com/.../ pendekatan-terintegrasi-untukperencanaan-tata-guna-lahan

Muchammad A.U.A., M.L. Ujianto, dan Idris. 2015. Evaluasi Karakteristik Keturunan Hail Persilangan antar Jagung Ketan Lokal (Zea mays ceritina Kulesh) dengan Jagung Manis Biji Putih (Zea mays saccharata). Skripsi (tidak dipublikasi)

Riwandi, M. Hadijaningsih, dan Hasanudin. 2014. Teknik Budidaya Jagung dengan Sistem Organik di Lahan Marjinal. ISBN 978-979-943184-4. UNIB Press 